\title{
The Grid of Burnout, Engagement and Job Satisfaction: a Case Study in Greece
}

\author{
George S. Androulakis (Corresponding author) \\ Dept. of Business Administration, University of Patras \\ 265.04 Patras, Greece \\ Dimitra Ap. Georgiou \\ Dept. of Business Administration, University of Patras \\ 265.04 Patras, Greece \\ George Nikolaou \\ Dept. of Education and Social Work, University of Patras \\ 265.04 Patras, Greece
}

Received: Oct. 12, 2021 Accepted: Nov. 12, $2021 \quad$ Online published: Nov. 22, 2021

doi:10.5296/ijhrs.v11i4.19087ＵRL: https://doi.org/10.5296/ijhrs.v11i4.19087

\begin{abstract}
Work engagement's relation with burnout intensively concerns the research community. A plethora of works has tried to interpret the kind of correlation of the above structures with reference to their structural elements and phenomena deriving from their common causal network. Therefore, in this research, the correlation between work engagement and burnout is investigated via their main structural elements and on the basis of job satisfaction's interpretive role. For this purpose, the responses of 561 employees from various economic sectors in Greece, were analyzed using path analysis after the data had first been approached via item response theory. Job satisfaction's interpretive role appeared to be of importance in regards to the positive sign of the correlation between work engagement and burnout as emerged in this work. The intrinsic job satisfaction's positive effect on both constructs that is burnout and work engagement, also arose as a research outcome, while the extrinsic job satisfaction appeared to operate positively to work engagement and negatively to burnout, regulating in this way the overall correlation exerted, therefore giving rise to theoretical and
\end{abstract}


practical implications.

Keywords: work engagement, burnout, job satisfaction, path analysis, item response theory

\section{Introduction}

The relationship between burnout and work engagement is still under consideration (Leon et al., 2015) as the two concepts seem to be highly correlated, representing in parallel topics of intense interest both in practice and theory (Halbesleben et al., 2009; Maricuţoiu et al., 2017). Burnout and work engagement have crucial results for employees' health and organizational performance (Christian et al., 2011; Maricuţoiu et al., 2017; Taris, 2006) where their success derives from the mechanisms that fully extract the benefit of human resources' abilities, knowledge and skills (Butakor et al., 2021; Pološki Vokić \& Hernaus, 2015).

With respect to the comprehension of these essential constructs, a plethora of remarkable approaches were given genesis. Certain regard burnout and work engagement as connected, opposite ends on a continuum arising from the same measure while other interpretations consider burnout and work engagement as independent states, interrelated though, consequently requiring different measurement tools (Cole et al., 2012; González-Romá et al., 2006; Leon et al., 2015; Maslach \& Leiter, 1997; W. B. Schaufeli \& Bakker, 2004b).

In total, the research is developed via various approaches towards burnout and work engagement relationship (Bakker \& Leiter, 2010; Maslach \& Leiter, 1997), with the purpose to comprehend the phenomena and their relationship in terms of both similarities and differences. In regards to the latter, the dialectical theory can accommodate the dynamics of the correlation (Leon et al., 2015) as it concerns opposite realities that interact to approach truths, involving the discussion and resolution of opposing arguments (Baxter \& Montgomery, 1996).

Burnout includes three main structural elements, namely emotional exhaustion - depletion of emotional resources, employees feel they can no longer offer at a psychological level -, low personal accomplishment - a sense of reduced self-efficacy, self-confidence at work (Maslach \& Jackson, 1981), and depersonalization - negative, cynical or distant attitude in the context of work itself and of the interpersonal relationships within it -, (Marek et al., 2017; W. B. Schaufeli et al., 2009). It is noted that the dimensions of exhaustion and cynicism are considered essentials to burnout (Green et al., 1991; Lee \& Ashforth, 1996; Maricuţoiu et al., 2017).

In regards to work engagement, it suggests a positive, affirmative and rewarding mentality, manifested through its three structural elements, that is absorption -continuous maintenance of complete, deep concentration and control over work-, vigor -high levels of spiritual strength and energy in the work environment, effort to invest in work and will to persevere in difficult situations-, and dedication -a sense of importance and enthusiasm for work, inspiration, pride and contemplation of work as a challenge- to work (Bakker \& Bal, 2010; Butakor et al., 2021). However, vigor and dedication are viewed as the central elements of work engagement (W. B. Schaufeli et al., 2008; W. Schaufeli \& Salanova, 2011). 
Nevertheless, according to Maslach and Leiter (1997), work engagement was defined based on the ground of energy, involvement, and absorption as opposed to burnout' three dimensions, exhaustion, cynicism/depersonalization, and efficacy, respectively. In terms of this logic, it was argued the utility of Maslach Burnout Inventory (MBI) to measure both phenomena -work engagement and burnout-, where low values of exhaustion and cynicism combined with high values of efficacy indicate work engagement (Leon et al., 2015; Maslach \& Leiter, 1997). Consequently, it was emphasized that work engagement and burnout constitute two opposite constructs (Cole et al., 2012; Maricuțoiu et al., 2017) and thus the former reflects the desired purpose of any intervention in terms of burnout (Maslach et al., 2012; Narainsamy \& Van Der Westhuizen, 2013). On the other hand, research shows that burnout and work engagement are interconnected structures, constituting through different forms of employee well-being (Maricuțoiu et al., 2017; W. Schaufeli \& Salanova, 2014).

In terms of the predictors of work engagement, control over work, salary, recognition, support, justice, and the compatibility of values with the working requirements, are considered as central (Crawford et al., 2010; Maslach \& Leiter, 1997); the psychological conditions of meaning at work that is safety and availability are also of significance (Crawford et al., 2010; Kahn, 1990).

Like work engagement, job satisfaction constitutes a positive situation (Hakanen et al., 2018) with its concept referring to an attitude that reflects the positive or negative feelings of the individual towards his/her work, colleagues and work environment (Hegar, 2011; Sudibjo \& Sutarji, 2020). Based on Hirschfeld's (2000) approach, job satisfaction expresses the extent to which people enjoy their job (Hirschfeld, 2000; Rothmann, 2008), while according to Granny, Smith and Stone (1992) it expresses a reaction to work, proceeding from the comparison between the actual and the expected results (Granny et al., 1992; Rothmann, 2008).

Job satisfaction is considered as a multidimensional structure composed of an exogenous and endogenous component; thus, the intrinsic job satisfaction has to do with the feelings of employees about the nature of their job duties while the extrinsic job satisfaction reflects the feelings about parameters of the work situation that are external to their job duties (Hirschfeld, 2000; Rothmann, 2008).

In other words, the intrinsic job satisfaction is viewed to relate to an individual's success to perform his/her work properly stemming from the presence of an internal factor related to job satisfaction with the characteristics of the work itself. In contrast, the extrinsic job satisfaction represents job satisfaction because of the influence of an external factor such as the individual's reward through salary, appreciation or recognition of success, and generally the things gained from the performance of his/her work (Novitasari et al., 2020). Indicatively, intrinsic, and extrinsic elements of job satisfaction can be approached via the Minnesota Job Satisfaction Questionnaire, (Weiss et al., 1967), where the intrinsic job satisfaction encompasses working aspects inherent to the very nature of it and are initially experienced by the employee on an internal level (sense of achievement, challenge). In the same line of argument, extrinsic job satisfaction relates to aspects external to the nature of the work (working conditions, job safety) (Golbasi et al., 2008). 


\section{MInstitute Machink $_{\text {Insthe }}$}

Nevertheless, the association of burnout with work engagement is characterized by complexity, as the two constructs appear to influence work behavior and interaction independently, including work performance and absence (Halbesleben et al., 2009; Hoxsey, 2010; James K. Harter et al., 2002; Leon et al., 2015). Due to the above complexity, the relationship between burnout and work engagement is under constant discussion (Cole et al., 2012; Leon et al., 2015; W. B. Schaufeli \& Bakker, 2010) and therefore several triggers are offered towards the clarification of the correlation, operation, and differentiation of the mechanisms between the two constructs (Cole et al., 2012; Leon et al., 2015).

Indeed, for the above distinct forms of employee well-being that is burnout, work engagement, and job satisfaction, very little is known about how they interact over time (Hakanen et al., 2018). The consideration of employee well-being as a multidimensional issue trapping subtle differentiation in work experiences induces the existing complication. Meanwhile, job satisfaction, burnout, work stress, and work engagement are crucial aspects of employees' emotional well-being (Cropanzano \& Wright, 2001; Rothmann, 2008). In this context, it might be useful to clarify the independence of the above dimensions or their relevance as parts of a more general dimension(Cropanzano \& Wright, 2001; Rothmann, 2008).

Towards this direction, based on Rothmann's (2008) approach of burnout, stress, job satisfaction and work engagement as dimensions of employee's well-being, it emerged the need for similar studies being conducted in a variety of work environments (Narainsamy \& Van Der Westhuizen, 2013; Rothmann, 2008). In the same line of argument, burnout -exhaustion and cynicism-, work engagement -vigor and dedication-, work stress -job demands and lack of job resources- and job satisfaction were examined in terms of the four-factor model of employee well-being (Narainsamy \& Van Der Westhuizen, 2013). Additional research has focused thoroughly on the interconnection between the above structures (Høigaard et al., 2012; W. B. Schaufeli \& Bakker, 2004a; Van der Colff \& Rothmann, 2009).

In the light of the previous approaches, the aim of the present work is to examine the relationship between burnout and work engagement under the spectrum of their common causal network related to job satisfaction, along with their structural elements' interactions.

Consequently, the following research questions arise:

1) Which are the inter-correlations developed between the constructs of job satisfaction and work engagement on the level of their structural elements?

2) Which are the inter-correlations developed between the constructs of job satisfaction and burnout on the level of their structural elements?

\section{Methodology}

The present survey was conducted in December 2019 and the target group was the general working population from various economic sectors in Greece. Thus, 1495 questionnaires were distributed of which 561 were valid and weighted by geographical distribution. The 


\section{Macrothink}

International Journal of Human Resource Studies

ISSN 2162-3058 2021, Vol. 11, No. 4

questionnaires enclosed indeed the purpose of the study and the statement of confidentiality and anonymity of the answers.

For the weighting of the sample in terms of geographical distribution, the data of the 2011 census was used based on Table B01 of the Hellenic Statistical Authority concerning fixed population by gender and age groups -from 15 to 67 years old-, (Hellenic Statistical Authority, 2011). Table 1 shows the gender and the age of the sample.

Table 1. Gender and age of the sample

\begin{tabular}{crrrrrr}
\hline & & \multicolumn{2}{c}{ Total } & \multicolumn{3}{c}{ Percentage } \\
\cline { 3 - 7 } Age & Total & F & M & F & M \\
\hline $15-19$ & 36 & 22 & 14 & 0.61 & 0.39 \\
$20-24$ & 171 & 91 & 80 & 0.53 & 0.47 \\
$25-29$ & 74 & 29 & 45 & 0.39 & 0.61 \\
$30-34$ & 53 & 21 & 32 & 0.40 & 0.60 \\
$35-39$ & 26 & 11 & 15 & 0.42 & 0.58 \\
$40-44$ & 50 & 28 & 22 & 0.56 & 0.44 \\
$45-49$ & 61 & 35 & 26 & 0.57 & 0.43 \\
$50-54$ & 58 & 25 & 33 & 0.43 & 0.57 \\
$55-59$ & 28 & 7 & 21 & 0.25 & 0.75 \\
$60-64$ & 3 & 1 & 2 & 0.33 & 0.67 \\
$65+$ & 1 & 1 & 0 & 1.00 & 0.00 \\
Total & 561 & 271 & 290 & 0.48 & 0.52 \\
\hline
\end{tabular}

The sectors according to the standard of the Statistical Economic Classification of Economic Activities of 2008 of the Hellenic Statistical Authority based on the analogous economic classification NACE rev.2 of the European Union are presented in Table 2, (Hellenic Statistical Authority, 2011). 
Table 2. Frequencies of the sample according to the economic sectors

\begin{tabular}{lccc}
\hline Economic classification of economic activities & Freq & \% Total & $\begin{array}{c}\text { \% Total } \\
\text { Cum. }\end{array}$ \\
\hline Other service activities & 118 & 21.03 & 21.03 \\
Wholesale and retail trade, repair of motor vehicles and motorcycles & 58 & 10.34 & 31.37 \\
Education & 55 & 9.80 & 41.18 \\
Arts, entertainment and recreation & 42 & 7.49 & 48.66 \\
Accommodation and catering & 41 & 7.31 & 55.97 \\
services & & & \\
Human health and social work & 34 & 6.06 & 62.03 \\
activities & & & \\
Construction & 29 & 5.17 & 67.20 \\
Financial and insurance activities & 27 & 4.81 & 72.01 \\
Professional, scientific and technical activities & 27 & 4.81 & 76.83 \\
Transport and storage & 20 & 3.57 & 80.39 \\
Public administration and defense & 19 & 3.39 & 83.78 \\
Agriculture, forestry and fisheries & 18 & 3.21 & 86.99 \\
Administrative and support & 16 & 2.85 & 89.84 \\
activities & & & \\
Information and communication & 15 & 2.67 & 92.51 \\
Supply of electricity, gas, steam and air conditioning & 13 & 2.32 & 94.83 \\
Processing & 9 & 1.60 & 96.43 \\
Activities of households as employers (domestic helpers, & 8 & 1.43 & 97.86 \\
concierges, babysitters, chauffeurs, gardeners, home teachers) & & & \\
Real estate management & 4 & 0.71 & 98.57 \\
Mining and quarrying & 3 & 0.53 & 99.11 \\
Activities of non-judicial organizations and bodies (e.g. the & 3 & 0.53 & 99.64 \\
European Union, the IMF, the OECD, the UN, etc.) & & & \\
\hline Water supply, wastewater treatment, waste management and & 2 & 0.36 & 100.00 \\
remediation activities & & & \\
\hline Total & $\mathbf{5 6 1}$ & $\mathbf{1 0 0 . 0 0}$ & $\mathbf{1 0 0 . 0 0}$ \\
\hline
\end{tabular}

In regard to the structure of the questionnaire the following parts are included:

- Demographic data (gender, age, education, marital status).

- Data on employment status (type of work, job position, supervisory or coordinating role, work experience, economic sector of work, average daily working hours).

- The Minnesota Job Satisfaction Questionnaire short form (MSQsf) was used to assess job satisfaction indicating how satisfied or dissatisfied are the respondents with their work (Weiss et al., 1967). It measures aspects of intrinsic and extrinsic satisfaction's dimensions and the overall satisfaction level. It encompasses 20 questions evaluated on a 5-point scale ranging from very dissatisfied to very satisfied. MSQsf measures predominantly extrinsic job satisfaction (6 items) - measuring environmental or extrinsic reinforcement factors (company policy and practice, working conditions, supervision, colleagues, insurance, human relations and leadership, wages) - and intrinsic job satisfaction (12 items) - measuring intrinsic reinforcement factors (type of work, achievement and ability utilization, recognition, feelings of independence; authority and responsibility; moral values, creativity and success) -, with the remaining 2 out of 20 questions employed only for the general scale (Tarcan et al., 2017; Weiss et al., 1967). Cronbach-a is 0.93 in total, 0.78 for extrinsic job satisfaction and 0.90 for intrinsic job satisfaction. 
- The Utrecht Work Engagement Scale (UWES17) (W. B. Schaufeli et al., 2002; W. B. Schaufeli \& Bakker, 2004b) was employed to assess work engagement by 17 items and 7-point scale from 0-"never" to 6-"daily". UWES17 items are categorized into three subscales expressing work engagement's three dimensions that is vigor (VI 6 items), dedication (DE 5 items) and absorption (AB 6 items). High values on dedication, vigor and absorption show high values of work engagement. Cronbach's alpha is greater than 0.7 in all categories that is total 0.95 , for dedication 0.89 , vigor 0.85 and for absorption 0.81 .

- The Maslach Burnout Inventory (MBI) (Kokkinos, 2006; Maslach et al., 1986; Maslach \& Jackson, 1981) assesses the level of burnout using a 7-point scale from 0-"never" to 6-“daily". The Maslach Burnout Inventory-Human Services Survey (MBI-HSS) is composed of the following sub-scales: emotional exhaustion (9 items), personal accomplishment (8 items), and depersonalization/cynicism (5 items). High values on exhaustion and depersonalization combined with low values on personal accomplishment are indicative of burnout. For the calculation of burnout score exclusively, personal accomplishment's items were reversed. The internal relevance coefficient is 0.86 and for the subscales is 0.73 for emotional exhaustion, 0.6 for depersonalization, and 0.77 for personal accomplishment.

The way the score is usually calculated in the constructions examined -burnout, work engagement and job satisfaction-, as well as in their structural elements is expressed as the sum of the scores of their items divided by the number of them and therefore, they follow the rules of Classical Test Theory (CTT) which is though characterized by certain disadvantages (Embretson \& Reise, 2013; Zanon et al., 2016). These disadvantages can be addressed using Item Response Theory (IRT) (De Ayala, 2013; Kamata \& Bauer, 2008) that can be applied with great success to Likert scale data (Ligtvoet et al., 2010). The invariance property consists of the most significant property of IRT, that is the latent characteristic's levels for the examinee are independent of the questions he/she is asked to answer and respectively the parameters of the questions are also independent of a specific sample (Embretson \& Reise, 2013; Reise, 2014). The invariance property permits researchers to link in an effective way diverse measurement scales of the same characteristic and compare examinees even if they answered on different questionnaires (Bortolotti et al., 2013; Embretson \& Reise, 2013; Zanon et al., 2016). For the above reasons and for the purpose of this work, all indices' measurements of the structures examined have been calculated via IRT.

In the framework of the research methodology was used additionally path analysis as is considered the core of multi-factorial statistical analysis on the basis of causality's concept (Kamata \& Bauer, 2008; Kline, 2015). In the context of the present study the following abbreviations were used to illustrate the structural elements examined: (ENG) work engagement, (eVI) vigor, (eDE) dedication, (eAB) absorption, (BU) burnout, (bEE) emotional exhaustion, (bPA) personal accomplishment, (bCY) depersonalization/cynicism, (SAT) job satisfaction, (sINT) intrinsic job satisfaction, (sEXT) extrinsic job satisfaction.

In regards to the limitations of the present research, it can be mentioned that the responses come from younger age groups and therefore the factors influenced by the specific age groups may be more prominent. Additionally, the research was addressed to the general 
population of employees and therefore to different occupational categories resulting in the analysis of the findings as a whole and not individually in each economic sector. Moreover, from Table 2 can be noticed that most employees in Greece are occupied in human services domains (Hellenic Statistical Authority, 2011). This can constitute a limitation of the research under the rationale that more responses deriving from non-human services sectors would add more, particularly compared to countries where employment in diverse non-human economic activities exists to a greater extent. Nevertheless, in terms of the above limitations' alleviation, IRT was employed for its invariance property where the sample-independent evaluation procedure exists.

\section{Numerical Results}

The statistical package R, (R Core Team, 2021), was used for data processing. In particular, libraries psych and summarytools were used for univariate analysis (Comtois, 2021; Revelle, 2021), factoMineR, GPArotation libraries for factor analysis (Bernaards \& Jennrich, 2014; Husson et al., 2020), lavaan, semPlot, metaSEM for path analysis models (M. Cheung, 2021; M. W.-L. Cheung, 2015; Epskamp, 2019; Rosseel, 2012; Rosseel et al., 2021) and the libraries readr, ggplot2, knitr for data visualization (Wickham et al., 2021; Wickham \& Hester, 2021; Xie, 2021).

Table 3 presents the basic statistical indicators of the examined constructs' structural elements. It indicates that the level of work engagement (0.509) is slightly higher than the level of burnout (0.483). In addition, the level of job satisfaction (0.417) appears lower than work engagement's (0.509) and that of burnout (0.483) and below the average. In addition, it can be observed that vigor (0.523) tends to increase the mean value of work engagement $(0.509)$ while dedication (0.494) and absorption (0.494) tend to decrease it. In terms of burnout, the average is increased by emotional exhaustion (0.556) while diminished by personal accomplishment (0.437).

Table 3. Descriptive statistics of the constructs' structural elements

\begin{tabular}{ccccccc}
\hline Structural element & n & mean & sd & skewness & kurtosis & se \\
\hline ENG & 561 & 0.509 & 0.321 & -0.065 & -1.423 & 0.014 \\
eVI & 561 & 0.523 & 0.327 & -0.129 & -1.466 & 0.014 \\
eDE & 561 & 0.494 & 0.358 & -0.004 & -1.589 & 0.015 \\
eAB & 561 & 0.494 & 0.272 & -0.042 & -1.226 & 0.011 \\
BU & 561 & 0.483 & 0.289 & 0.246 & -1.203 & 0.012 \\
bEE & 561 & 0.556 & 0.178 & 0.049 & -0.831 & 0.008 \\
bPA & 561 & 0.437 & 0.224 & 0.293 & -1.030 & 0.009 \\
bCY & 561 & 0.456 & 0.216 & 0.185 & -1.031 & 0.009 \\
SAT & 561 & 0.417 & 0.225 & -0.003 & -1.014 & 0.009 \\
sINT & 561 & 0.414 & 0.237 & -0.044 & -1.098 & 0.010 \\
SEXT & 561 & 0.482 & 0.242 & -0.094 & -1.049 & 0.010 \\
ENG & 561 & 0.509 & 0.321 & -0.065 & -1.423 & 0.014 \\
\hline
\end{tabular}

Table 4 illustrates the correlations of work engagement, burnout and job satisfaction and their structural elements respectively. It can be noticed that work engagement, burnout and job satisfaction develop positive correlations between them. 
Figures 1-7 depict path analysis models encompassing root mean square error of approximation (RMSEA) that equals to 0.035, comparative fit index (CFI) that equals to 0.941, and Tucker-Lewis index (TLI) that equals to 0.912 .

Table 4. Correlations of work engagement, burnout and job satisfaction and their structural elements

\begin{tabular}{|c|c|c|c|c|c|c|c|c|c|c|}
\hline & ENG & eVI & $\mathrm{eDE}$ & $\mathrm{eAB}$ & $\mathrm{BU}$ & bEE & bPA & $\mathrm{bCY}$ & SAT & sINT \\
\hline \multicolumn{11}{|l|}{ ENG } \\
\hline eVI & $0.93^{* * * *}$ & & & & & & & & & \\
\hline eDE & $0.94 * * *$ & $0.80^{* * * *}$ & & & & & & & & \\
\hline $\mathrm{eAB}$ & $0.90 * * *$ & $0.80^{* * * *}$ & $0.78^{* * *}$ & & & & & & & \\
\hline $\mathrm{BU}$ & $0.34 * * *$ & $0.35^{* * * *}$ & $0.35^{* * * *}$ & $0.29 * * *$ & & & & & & \\
\hline bEE & 0.06 & 0.04 & $0.09 *$ & $0.09 *$ & $0.77^{* * * *}$ & & & & & \\
\hline bPA & $-0.51 * * *$ & $-0.52 * * *$ & $-0.49 * * *$ & $-0.42 * * *$ & $-0.77 * * *$ & $-0.40 * * *$ & & & & \\
\hline $\mathrm{bCY}$ & $0.21 * * *$ & $0.23^{* * * *}$ & $0.21 * * *$ & $0.16^{* * * *}$ & $0.77^{* * * *}$ & $0.45^{\text {**** }}$ & $-0.44 * * *$ & & & \\
\hline SAT & $0.55^{* * * *}$ & $0.49^{* * * *}$ & $0.56^{* * *}$ & $0.45^{* * * *}$ & $0.22^{* * * *}$ & 0.02 & $-0.35 * * *$ & $0.15^{* * *}$ & & \\
\hline sINT & $0.56^{* * * *}$ & $0.50^{* * *}$ & $0.57 * * *$ & $0.46^{* * * *}$ & $0.26^{* * *}$ & 0.04 & $-0.38 * * *$ & $0.18 * * *$ & $0.96^{* * *}$ & \\
\hline sEXT & $0.39^{* * *}$ & $0.33^{* * *}$ & $0.40^{* * * *}$ & $0.33^{* * *}$ & $0.09 *$ & -0.05 & $-0.19 * * *$ & 0.05 & $0.84^{* * *}$ & $0.68 * *$ \\
\hline
\end{tabular}

In Figure 1, it can be observed that job satisfaction has a positive effect on both work engagement (0.55) and burnout (0.22). The first is much stronger than the later but the positive effect of job satisfaction on burnout is still noted. It is also noteworthy that within the part of work engagement and burnout not interpreted by the effect of job satisfaction, a positive (0.27) correlation between them emerges.

Figure 2 indicates that the extrinsic job satisfaction does not show a statistically significant correlation with work engagement as opposed to the intrinsic job satisfaction that exerts positive (0.54) correlation to work engagement.

Figure 3 indicates the effect of extrinsic and intrinsic job satisfaction to work engagement via the structural elements of the latter. In particular, it is illustrated that in terms of the work engagement's structural elements, dedication shows the greatest positive (0.58) effect, followed by vigor (0.44) and lastly by absorption (0.36). In addition, examining how intrinsic job satisfaction positively mediates the effect on work engagement's structural elements, it emerges that the greatest effect is exerted mainly via dedication (0.55) and vigor (0.52) and then via absorption (0.44). It is also observed that extrinsic job satisfaction does not exert a statistically significant influence on the structural elements of work engagement.

According to the effect of job satisfaction on burnout, from Figure 4 it is noted that the intrinsic job satisfaction is positively correlated with burnout $(0.36)$ while the extrinsic job satisfaction exerts a negative (-0.15) correlation with the latter. Because of the fact that the effect of intrinsic job satisfaction is greater than the effect of the extrinsic, the overall correlation of job satisfaction with burnout emerges with a positive sign. 


\section{Macrothink}

International Journal of Human Resource Studies

ISSN 2162-3058 2021, Vol. 11, No. 4

Figure 5 illustrates the effect of extrinsic and intrinsic job satisfaction on burnout via the latest' structural elements. Therefore, the intrinsic job satisfaction exerts a positive effect on burnout via mainly personal accomplishment. On the contrary, extrinsic job satisfaction appears to develop a negative correlation with approximately equal - in absolute valuesloadings with all burnout's structural elements.

It follows the coexistence of burnout and work engagement as dependent variables along with their structural elements, employing extrinsic and intrinsic job satisfaction as interpretive variables.

Figure 6 illustrates that intrinsic job satisfaction exerts greater positive (0.54) effect on work engagement compared to burnout (0.36). On the contrary, extrinsic job satisfaction appears to develop a weak negative (-0.15) influence on burnout while it exerts no statistically significant influence on work engagement.

As a union of Figures 3 and 5, Figure 7 presents the interrelations of extrinsic and intrinsic job satisfaction with burnout and work engagement's structural elements.

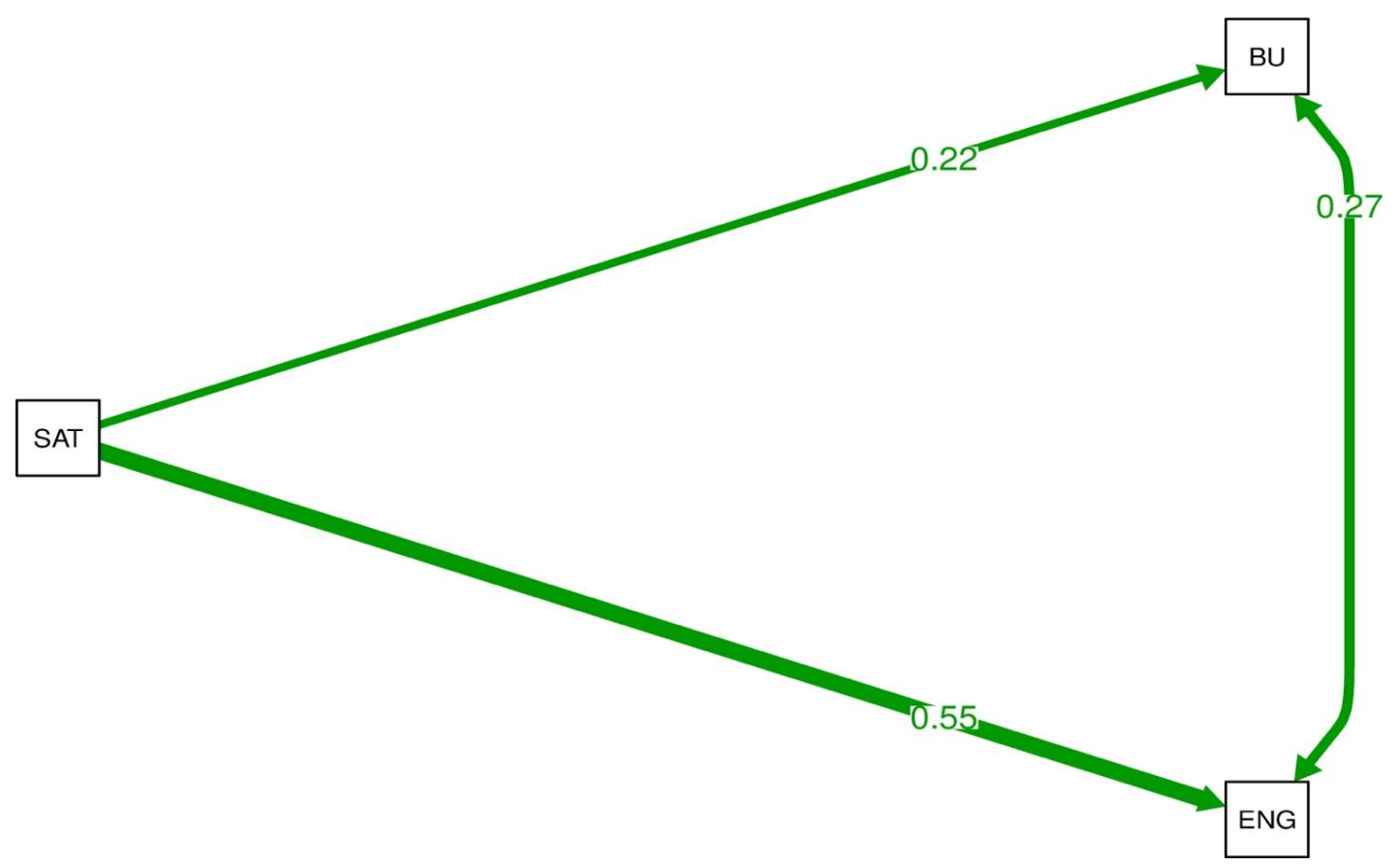

Figure 1. Model of job satisfaction with burnout and work engagement 


\section{Macrothink

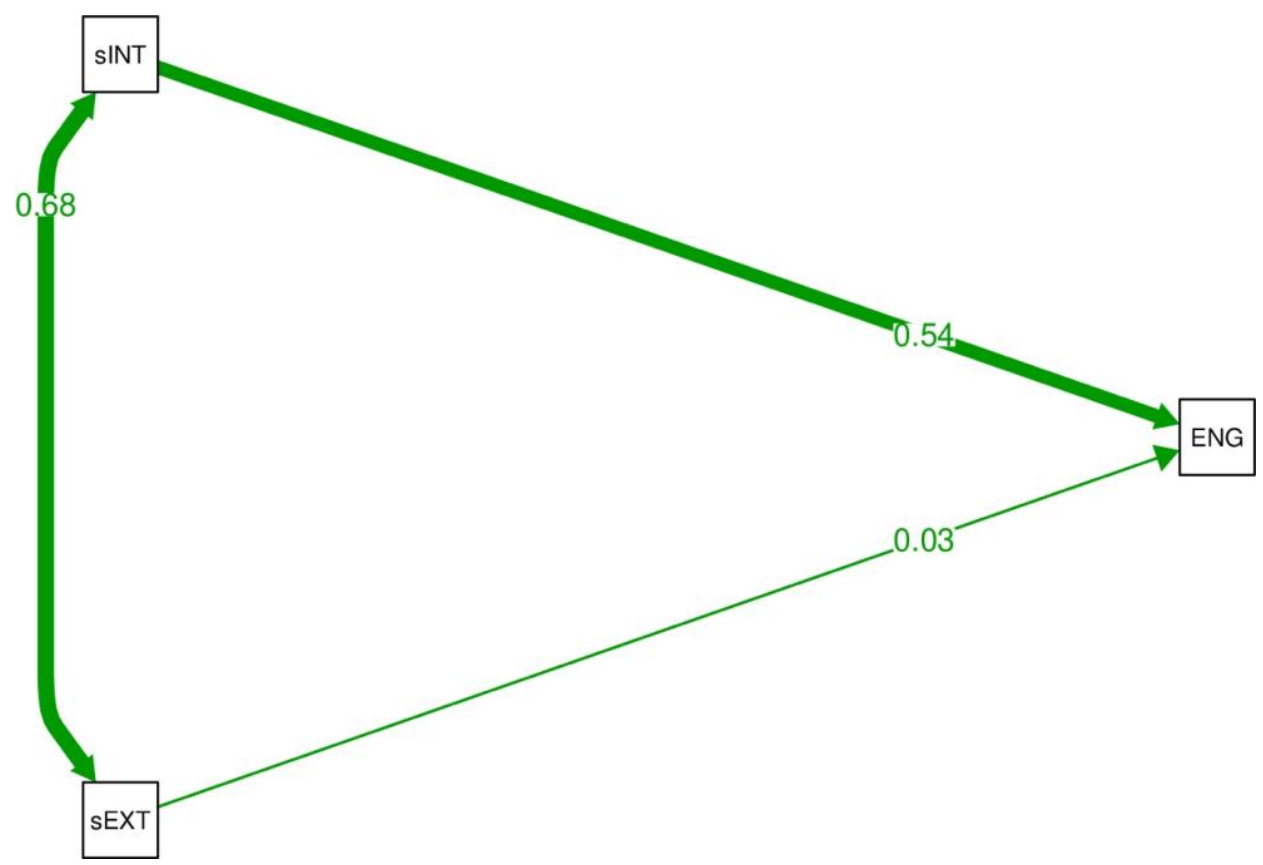

Figure 2. Model of internal and extrinsic job satisfaction with work engagement

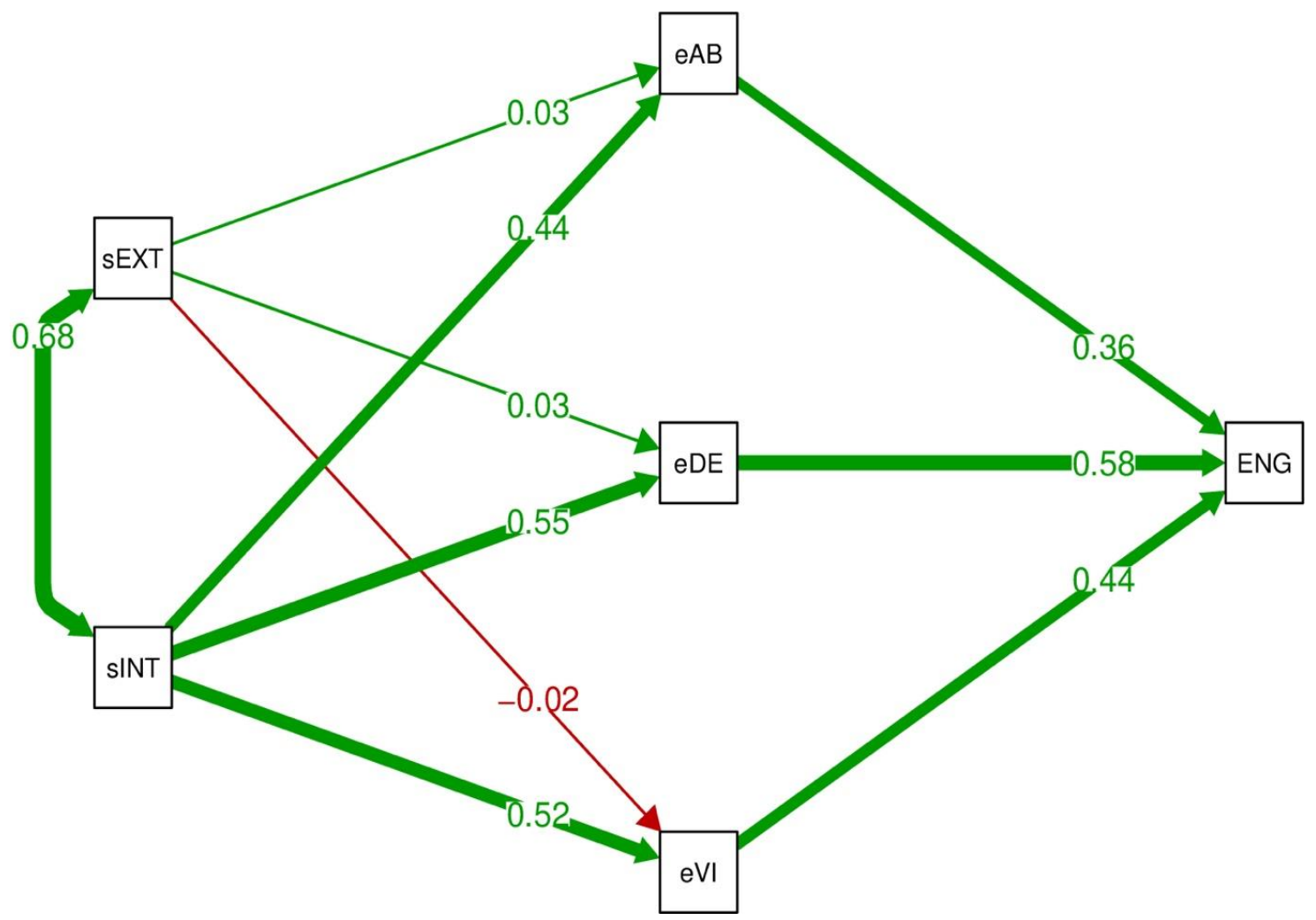

Figure 3. Model of internal and extrinsic job satisfaction with work engagement via its structural elements 


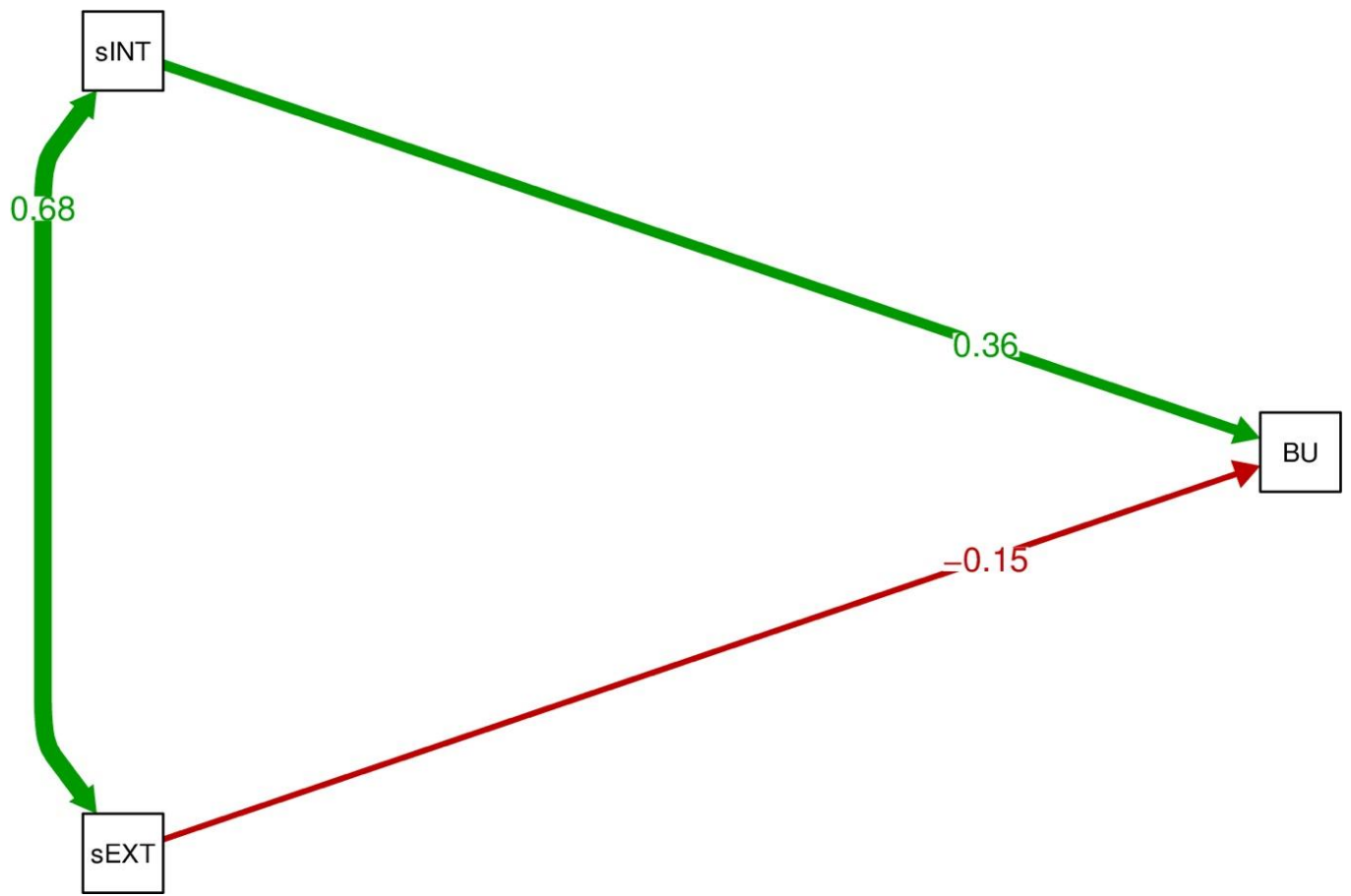

Figure 4. Model of internal and extrinsic job satisfaction with burnout

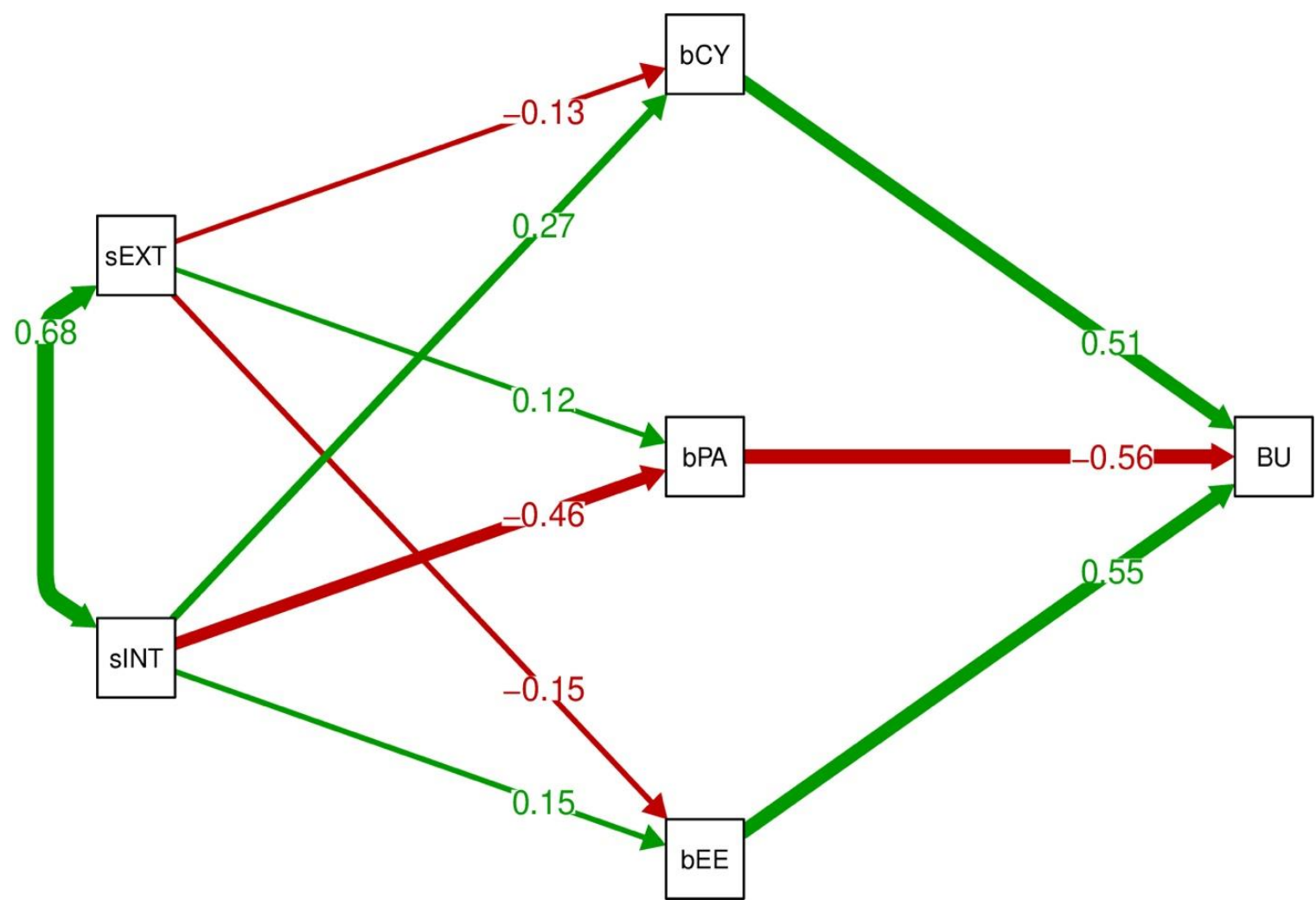

Figure 5. Model of internal and extrinsic job satisfaction with burnout via its structural elements 


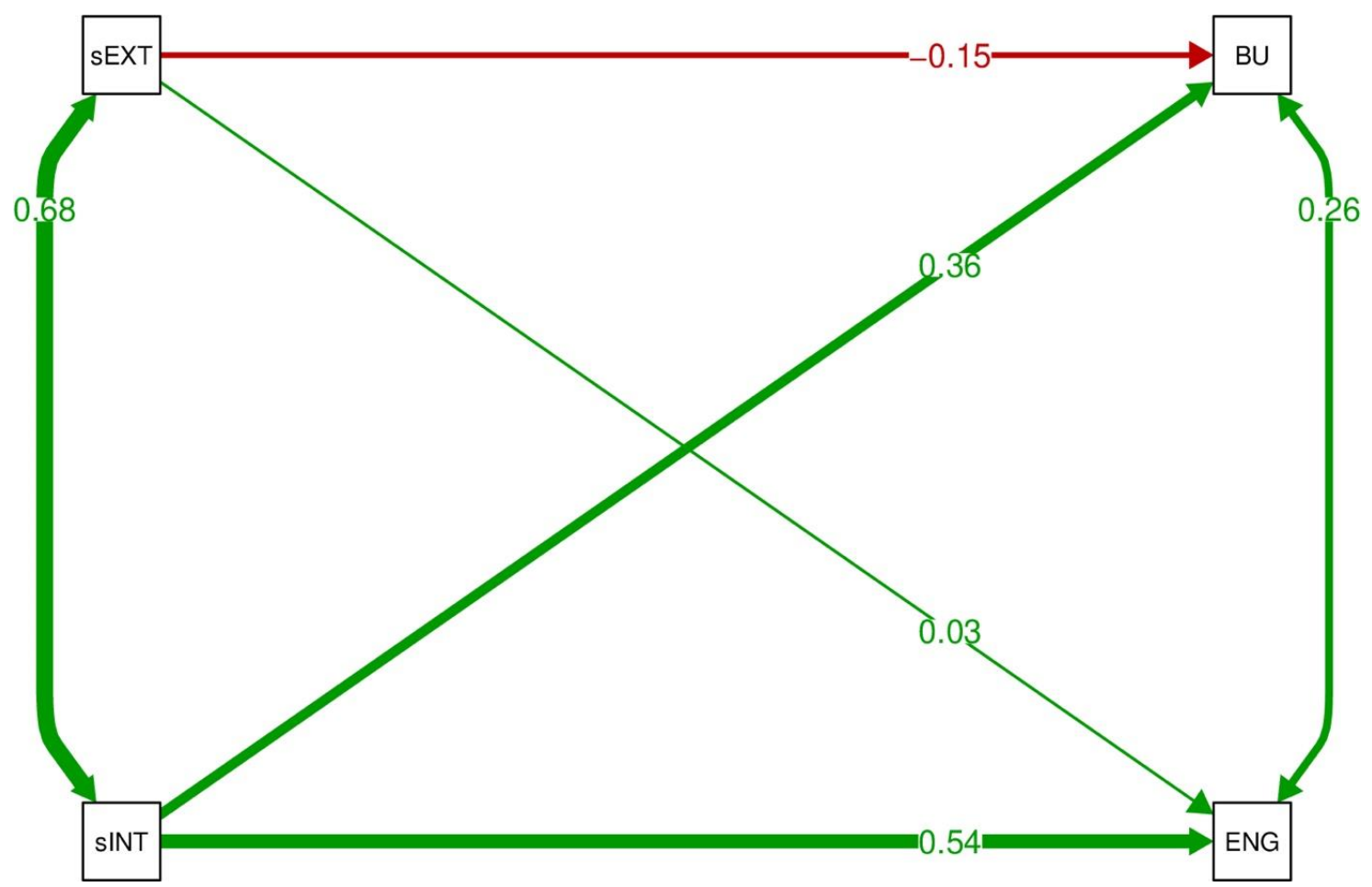

Figure 6. Model of internal and extrinsic job satisfaction with work engagement and burnout

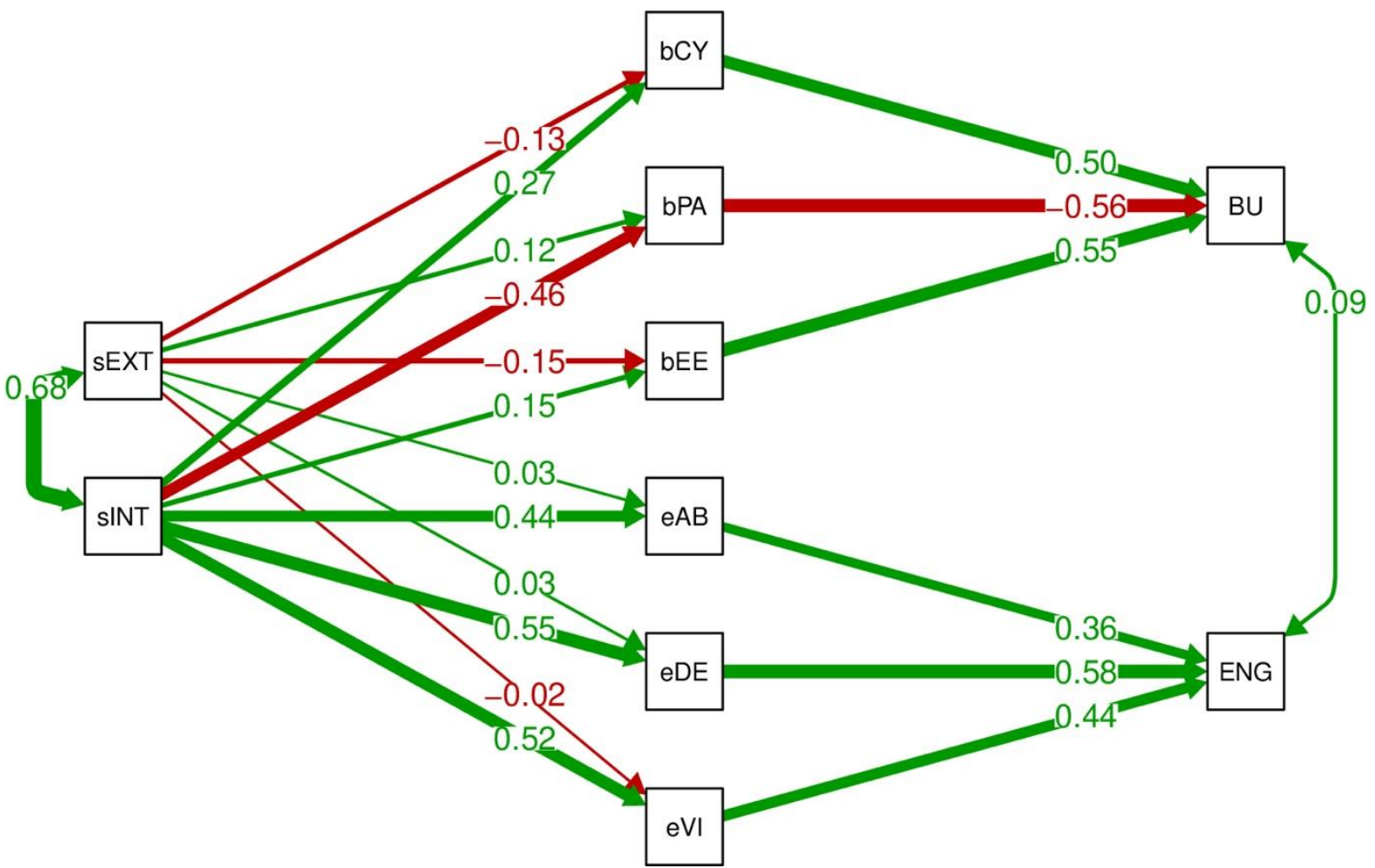

Figure 7. Model of internal and extrinsic job satisfaction with work engagement and burnout via their structural elements 


\section{Discussion}

The purpose of this work was to examine the interactive connection between burnout and work engagement under the spectrum of job satisfaction's interpretive role. In addition, the present study focused on the inter-correlations exercised by the structural components of the above constructs, towards the clarification of the interconnections' complexity along with the decomposition of the functions' complication, as they emerged.

Therefore, the numerical results of the present research indicated that the part of work engagement and burnout not affected by a common set of causes related to job satisfaction develops a positive correlation. In that sense, there may exist a ground of reasons independent of job satisfaction exerting a positive effect on both phenomena that is burnout and work engagement. This leads us to think that the relationship between burnout and work engagement is not surrounded by a "fort" and therefore can maintain an unchanged sign correlation but instead, there are perhaps external factors not relevant to job satisfaction, that if prevail under the appropriate conditions, can change the correlation's sign.

In regards to the above, according to Schaufeli and Bakker (2004), burnout and work engagement represent more distinct situations where the connection is moderate to strongly negative (W. B. Schaufeli \& Bakker, 2004a) while on the other hand, where the two states are considered as opposite ends of a single structure, the "neutral zone" where neither burnout nor work engagement dominates, does not appear to be explained enough. In further, based on the finding of this work where between burnout and work engagement a positive correlation emerges, our thoughts are oriented towards the approach of the two phenomena as not opposite poles of the same structure, whereas if the above correlation emerged with a negative sign, then perhaps the scenario of two diametrically opposite ends could be encouraged.

The approach of the above constructs like a dipole is neither encouraged by the findings of Taris et al. (2017), where appears no contradiction between the states of burnout and work engagement (Taris et al., 2017), neither as opposite ends in the common dipole (Russell \& Carroll, 1999). In the same line of argument, in the research of Crawford et al. (2010), the phenomena examined are documented as discrete states (Crawford et al., 2010), with distinct networks of conceptual effects (Crawford et al., 2010; Goering et al., 2017; W. B. Schaufeli $\&$ Bakker, 2004a). In this way, common work elements can produce varying levels of burnout and work engagement simultaneously experienced by employees (W. B. Schaufeli et al., 2008; Timms et al., 2012).

Remaining on the issue of the positive sign of the correlation between burnout and work engagement, we can recall the research of Goering et al. (2017) where a positive correlation between the two structures emerged on average; the interpretation given is that the relationship is probably more complex, for example -high power distance cultures- and thus, it appears that there exists a combination of mediating factors affecting it (Goering et al., 2017).

In regards to the mediating factors, job satisfaction's role emerged in the present study of 
considerable significance in terms of the duality of its structural elements that is external and internal satisfaction. In further, the negative correlation between burnout and work engagement may occur mainly via the extrinsic job satisfaction's negative effect on burnout provided that it overweighs the positive effect exerted on burnout by the intrinsic job satisfaction. Therefore, it seems that aspects of employees' extrinsic job satisfaction, i.e., issues of the working situation external to the very nature of their work play a regulatory role towards the overall negative or positive sign of the correlation between work engagement and burnout.

In terms of the relationship between job satisfaction and work engagement, it appears that they are constructs moderately correlated, that can be differentiated from each other under the rationale that work engagement refers to a more active situation as opposed to job satisfaction reflecting a less active state (Bakker \& Oerlemans, 2011; W. B. Schaufeli, 2017).

In respect to the first research question of the present work, it emerged that the extrinsic job satisfaction does not show a significant correlation with work engagement whereas the intrinsic job satisfaction appears to have a positive correlation with the latter. That is, internally satisfied employees tend to engage which means that the positive correlation is based on the relationship between individuals' work engagement and how they feel about the very nature of their work. In other words, the "bond" between engagement to work and internal satisfaction with work arises remarkably, evoking thoughts about how important it is to have people who enjoy their work at its very nature, if work engagement is the desired goal. Job satisfaction's positive effect on work engagement was highlighted in the study by Sudibjo $\&$ Sutarji (2020), and in the research of Goering et al. (2017) where emerged that on average, work engagement relates to higher levels of job satisfaction; nevertheless, in the later study, given the high degree of heterogeneity, there exist subgroups within the population where high scores of work engagement led to lower scores of job satisfaction, witnessing a variety of factors, many of which have not yet been addressed playing thought a regulatory role (Goering et al., 2017; Sudibjo \& Sutarji, 2020).

In the present study, examining the mediation mechanism of job satisfaction's elements on work engagement, it arose that intrinsic job satisfaction mediates the effect positively on all three structural elements of work engagement, with the greatest influence being mediated through dedication and vigor and lastly absorption. Thus, when the levels of an individual's intrinsic job satisfaction are high -the employee is satisfied with the very nature of the work-, then the mediation of the effect takes place primarily on the enthusiasm, perception of the work as a challenge and effort to invest and overcome difficulties. Later on, the effect is exerted on absorption.

In regards to the second research question posed in the present work, it emerged that intrinsic job satisfaction is positively correlated with burnout while in the case of extrinsic job satisfaction, the correlation appears negative. In this sense, the overall positive correlation of job satisfaction with burnout can be interpreted under the assumption that the intrinsic job satisfaction's effect is greater than the influence exerted by the extrinsic job satisfaction. An interpretation that could be given is that when the employee enjoys the very nature of his/her 
work, may devote more time working on it or invest more personal sources of energy and therefore burnout may occur due to this excessive use of available personal resources. At this point we can recall an additional concern referring to the time sequence of different categories of employee well-being; indicatively, it has been highlighted that work engagement is capable of leading to workaholism (Bakker et al., 2011) or to burnout alternatively (Hakanen et al., 2018; W. Schaufeli \& Salanova, 2011).

In the present study and on the level of the structural elements' mediation emerged that the intrinsic job satisfaction exerts a positive effect on depersonalization/cynicism and emotional exhaustion while negative -and greater in absolute values- on personal accomplishment, as burnout's structural components. On the other hand, the extrinsic job satisfaction emerged to have a negative correlation with burnout with approximately equal loadings on absolute values on all burnout's structural elements. It seems therefore, that when the employee is satisfied with aspects of the work external to the nature of it, this plays a deterrent role towards burnout on the basis of all its structural elements. According to Rothmann (2008), exhaustion and cynicism as burnout's dimensions, and vigor and dedication of work engagement, emerged to be significantly associated with both internal and external job satisfaction (Rothmann, 2008). Based on the research by Tarcan et al. (2017) a negative correlation emerged between job satisfaction and burnout's structural elements (Tarcan et al., 2017). In further, according to Kebapçı \& Akyolcu (2011), it emerged a positive correlation between depersonalization and emotional exhaustion while job satisfaction and personal accomplishment were significantly negative related (Kebapçı \& Akyolcu, 2011; Tarcan et al., 2017). Nevertheless, according to the research of Narainsamy and Van Der Westhuizen (2013), exhaustion and cynicism have an important negative association with both intrinsic and extrinsic job satisfaction and at the same time, a negative connection with vigor and dedication. In addition, both vigor and dedication show positive correlation with both internal and extrinsic job satisfaction (Narainsamy \& Van Der Westhuizen, 2013).

In regards to all the above, in this work an effort was made towards the examination of job satisfaction as an interpretive factor of work engagement and burnout. The main finding reflects that the negative or positive correlation between burnout and work engagement lies in the level of the employees' extrinsic job satisfaction, that is how satisfied they are with the aspects external to the very nature of their work. That is, the level of burnout is reduced while work engagement is increased, mainly when the employee is satisfied with the aspects of the work "not inherent" in it, but rather operating externally to the very nature of the work. These aspects as presented in the introduction, could be for instance, the working conditions, the salary, the job safety. On the other hand, in the case where the employees are satisfied with the elements in regards to the nature of their work (likewise sense of achievement, level of independence), it appears that the burnout's level is increased along with work engagement. A possible interpretation is that when the individual enjoys his/her work at the very nature of it and at such a level leading him/her to additional emotional or physical investment or exaggeration of the working hours, this may evoke or induce burnout. Nevertheless, the existence of the intrinsic job satisfaction deriving from the joy from the very nature of the work appears as connected with high levels of work engagement. 


\section{$\Lambda$ Macrothink}

International Journal of Human Resource Studies

ISSN 2162-3058

2021, Vol. 11, No. 4

The responses to the research questions posed in this work may be useful on a theoretical as well as on a practical basis, despite the existing shortcomings. Meanwhile, in terms of future research, other constructs like emotional intelligence could be examined as interpretive variables of work engagement and burnout.

As for the contribution of the present work, we can recall that it is crucial on a theoretical and practical level to examine the potential results of diverse types of employee well-being as well as the comparisons between them (Hakanen et al., 2018). Particularly, in constructs like burnout, work engagement, job satisfaction where, as described above, the complexity is "inherent", the analysis and the examination of their interrelationships can contribute towards the decomposition of their structures along with the comprehension of their functions.

In respect to the latter, that is the contribution on a practical level, we take into consideration that in contrast to the past where research was more focused on understanding pathology, there is now a shift into exploring how positive aspects can be encouraged (Goering et al., 2017; Seligman \& Csikszentmihalyi, 2014); such as "how to reduce burnout" and "how to increase work engagement" (Goering et al., 2017). With these thoughts, the present work highlights along with the recognition of the intrinsic job satisfaction's importance, the significance of strengthening more the employee's extrinsic job satisfaction in such a way that empowers factors and encourages conditions that surround the "fort" of the very nature of the work, for they seem to act simultaneously as a deterrent to burnout and as a boost to work engagement.

As a synopsis, the enlightenment of the mediating factors existing on the spectrum of work engagement and burnout is of considerable attention along with the decomposition of their mechanism's complexity. Therefore, the synthesis of the complete "picture" based on the unceasing, thorough and even dialectical comprehension can impart to work development, employee prosperity, and social well-being.

\section{References}

Bakker, A. B., Albrecht, S. L., \& Leiter, M. P. (2011). Key questions regarding work engagement. European Journal of Work and Organizational Psychology, 20(1), 4-28. https://doi.org/10.1080/1359432X.2010.485352

Bakker, A. B., \& Bal, M. P. (2010). Weekly work engagement and performance: A study among starting teachers. Journal of Occupational and Organizational Psychology, 83(1), 189-206. https://doi.org/https://doi.org/10.1348/096317909X402596

Bakker, A. B., \& Leiter, M. P. (2010). Work engagement: A handbook of essential theory and research. Psychology press.

Bakker, A. B., \& Oerlemans, W. (2011). Subjective well-being in organizations. The Oxford Handbook of Positive Organizational Scholarship, 49, 178-189.

Baxter, L. A., \& Montgomery, B. M. (1996). Relating: Dialogues and dialectics. Guilford Press. 
Bernaards, C., \& Jennrich, R. (2014). GPArotation: GPA Factor Rotation. http://www.stat.ucla.edu/research/gpa

Bortolotti, S. L. V., Tezza, R., de Andrade, D. F., Bornia, A. C., \& de Sousa Júnior, A. F. (2013). Relevance and advantages of using the item response theory. Quality and Quantity, 47(4), 2341-2360. https://doi.org/10.1007/s11135-012-9684-5

Butakor, P. K., Guo, Q., \& Adebanji, A. O. (2021). Using structural equation modeling to examine the relationship between Ghanaian teachers' emotional intelligence, job satisfaction, professional identity, and work engagement. Psychology in the Schools, 58(3), 534-552. https://doi.org/https://doi.org/10.1002/pits.22462

Cheung, M. (2021). metaSEM: Meta-Analysis using Structural Equation Modeling. https://github.com/mikewlcheung/metasem

Cheung, M. W.-L. (2015). \{metaSEM\}: An R Package for Meta-Analysis using Structural Equation Modeling. Frontiers in Psychology, 5(1521). https://doi.org/10.3389/fpsyg.2014.01521

Christian, M. S., Garza, A. S., \& Slaughter, J. E. (2011). Work engagement: a quantitative review and test of its relations with task and contextual performance. Personnel Psychology, 64(1), 89-136. https://doi.org/https://doi.org/10.1111/j.1744-6570.2010.01203.x

Cole, M. S., Walter, F., Bedeian, A. G., \& O’Boyle, E. H. (2012). Job Burnout and Employee Engagement: A Meta-Analytic Examination of Construct Proliferation. Journal of Management, 38(5), 1550-1581. https://doi.org/10.1177/0149206311415252

Comtois, D. (2021). summarytools: Tools to Quickly and Neatly Summarize Data. https://github.com/dcomtois/summarytools

Crawford, E. R., LePine, J. A., \& Rich, B. L. (2010). Linking job demands and resources to employee engagement and burnout: a theoretical extension and meta-analytic test. Journal of Applied Psychology, 95(5), 834. https://doi.apa.org/doiLanding?doi=10.1037\%2Fa0019364

Cropanzano, R., \& Wright, T. A. (2001). When a" happy" worker is really a" productive" worker: A review and further refinement of the happy-productive worker thesis. Consulting $\begin{array}{lllll}\text { Psychology Journal: } \quad \text { Practice } & \text { and }\end{array}$ https://psycnet.apa.org/record/2001-18751-005

De Ayala, R. J. (2013). The theory and practice of item response theory. Guilford Publications.

Embretson, S. E., \& Reise, S. P. (2013). Item response theory. Psychology Press.

Epskamp, S. (2019). semPlot: Path Diagrams and Visual Analysis of Various SEM Packages' Output. https://github.com/SachaEpskamp/semPlot

Goering, D. D., Shimazu, A., Zhou, F., Wada, T., \& Sakai, R. (2017). Not if, but how they differ: A meta-analytic test of the nomological networks of burnout and engagement. Burnout Research, 5, 21-34. https://doi.org/https://doi.org/10.1016/j.burn.2017.05.003 


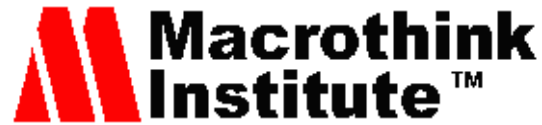

International Journal of Human Resource Studies

ISSN 2162-3058

Golbasi, Z., Kelleci, M., \& Dogan, S. (2008). Relationships between coping strategies, individual characteristics and job satisfaction in a sample of hospital nurses: Cross-sectional questionnaire survey. International Journal of Nursing Studies, 45(12), 1800-1806. https://doi.org/https://doi.org/10.1016/j.ijnurstu.2008.06.009

González-Romá, V., Schaufeli, W. B., Bakker, A. B., \& Lloret, S. (2006). Burnout and work engagement: Independent factors or opposite poles? Journal of Vocational Behavior, 68(1), 165-174. https://doi.org/10.1016/j.jvb.2005.01.003

Granny, C., Smith, P., \& Stone, E. F. (1992). Job satisfaction: Advances in research and application. Lexington, MA: Lexington Books.

Green, D. E., Walkey, F. H., \& Taylor, A. J. (1991). The three-factor structure of the Maslach Burnout Inventory: A multicultural, multinational confirmatory study. Journal of Social Behavior \& Personality, 6(3), 453-472.

Hakanen, J. J., Peeters, M. C. W., \& Schaufeli, W. B. (2018). Different types of employee well-being across time and their relationships with job crafting. Journal of Occupational Health Psychology, 23(2), 289. http://dx.doi.org/10.1037/ocp0000081

Halbesleben, J. R. B. B., Harvey, J., \& Bolino, M. C. (2009). Too engaged? A conservation of resources view of the relationship between work engagement and work interference with family. Journal of Applied Psychology, 94(6), 1452. https://doi.org/10.1037/a0017595

Hegar, K. (2011). Modern human relations at work. Nelson Education.

Hellenic Statistical Authority. (2011). NACE: Business Economy by Sector Table A02. Hellenic Statistical Authority. https://www.statistics.gr/

Hirschfeld, R. R. (2000). Does revising the intrinsic and extrinsic subscales of the Minnesota Satisfaction Questionnaire short form make a difference? Educational and Psychological Measurement, 60(2), 255-270.

Høigaard, R., Giske, R., \& Sundsli, K. (2012). Newly qualified teachers' work engagement and teacher efficacy influences on job satisfaction, burnout, and the intention to quit. European Journal of Teacher Education, 35(3), 347-357. https://doi.org/10.1080/02619768.2011.633993

Hoxsey, D. (2010). Are happy employees healthy employees? Researching the effects of employee engagement on absenteeism. Canadian Public Administration, 53(4), 551-571. https://doi.org/https://doi.org/10.1111/j.1754-7121.2010.00148.x

Husson, F., Josse, J., Le, S., \& Mazet, J. (2020). FactoMineR: Multivariate Exploratory Data Analysis and Data Mining. http://factominer.free.fr

James K. Harter, Frank L. Schmidt, Theodore L. Hayes, Harter, J. K., Schmidt, F. L., \& Hayes, T. L. (2002). Business-unit-level relationship between employee satisfaction, employee engagement, and business outcomes: A meta-analysis. Journal of Applied Psychology, 87(2), 268-279. https://doi.org/10.1037//0021-9010.87.2.268 
Kahn, W. A. (1990). Psychological conditions of personal engagement and disengagement at work. Academy of Management Journal, 33(4), 692-724.

Kamata, A., \& Bauer, D. J. (2008). A note on the relation between factor analytic and item response theory models. Structural Equation Modeling: A Multidisciplinary Journal, 15(1), 136-153. https://doi.org/10.1080/10705510701758406

Kebapçı, A., \& Akyolcu, N. (2011). Acil birimlerde çalışan hemşirelerde çalışma ortamının tükenmişlik düzeylerine etkisi. Türkiye Acil Tıp Dergisi, 11(2), 59-67.

Kline, R. B. (2015). Principles and practice of structural equation modeling. Guilford publications.

Kokkinos, C. M. (2006). Factor structure and psychometric properties of the Maslach Burnout Inventory-Educators Survey among elementary and secondary school teachers in Cyprus. Stress and Health, 22(1), 25-33. https://doi.org/10.1002/smi.1079

Lee, R. T., \& Ashforth, B. E. (1996). A meta-analytic examination of the correlates of the three dimensions of job burnout. Journal of Applied Psychology, 81(2), 123-133. https://doi.org/https://doi.apa.org/doi/10.1037/0021-9010.81.2.123

Leon, M. R., Halbesleben, J. R. B., \& Paustian-Underdahl, S. C. (2015). A dialectical perspective on burnout and engagement. Burnout Research, 2(2), 87-96. https://doi.org/https://doi.org/10.1016/j.burn.2015.06.002

Ligtvoet, R., Van der Ark, L. A., te Marvelde, J. M., \& Sijtsma, K. (2010). Investigating an invariant item ordering for polytomously scored items. Educational and Psychological Measurement, 70(4), 578-595.

Marek, T., Schaufeli, W. B., \& Maslach, C. (2017). Professional burnout: Recent developments in theory and research. Routledge.

Maricuțoiu, L. P., Sulea, C., \& Iancu, A. (2017). Work engagement or burnout: Which comes first? A meta-analysis of longitudinal evidence. Burnout Research, 5, 35-43. https://doi.org/https://doi.org/10.1016/j.burn.2017.05.001

Maslach, C., \& Jackson, S. E. (1981). The measurement of experienced burnout. Journal of Occupational Behaviour, 2, 99-113. https://doi.org/10.1002/job.4030020205

Maslach, C., Jackson, S. E., Leiter, M. P., Schaufeli, W. B., \& Schwab, R. L. (1986). Maslach burnout inventory (Vol. 21). Consulting psychologists press Palo Alto, CA.

Maslach, C., \& Leiter, M. P. (1997). The truth about burnout: How organizations cause personal stress and what to do about it. John Wiley \& Sons.

Maslach, C., Leiter, M. P., \& Jackson, S. E. (2012). Making a significant difference with burnout interventions: Researcher and practitioner collaboration. Journal of Organizational Behavior, 33(2), 296-300. https://doi.org/https://doi.org/10.1002/job.784

Narainsamy, K., \& Van Der Westhuizen, S. (2013). Work Related Well-Being: Burnout, Work 
Engagement, Occupational Stress and Job Satisfaction Within a Medical Laboratory Setting. Journal of Psychology in Africa, 23(3), 467-474. https://doi.org/10.1080/14330237.2013.10820653

Novitasari, D., Asbari, M., Wijaya, M. R., \& Yuwono, T. (2020). Effect of Organizational Justice on Organizational Commitment: Mediating Role of Intrinsic and Extrinsic Satisfaction. International Journal of Science and Management Studies (IJSMS), 3(3), 96-112. http://www.ijsmsjournal.org/2020/volume-3 issue-3/ijsms-v3i3p110.pdf

Pološki Vokić, N., \& Hernaus, T. (2015). The triad of job satisfaction, work engagement and employee loyalty-The interplay among the concepts. EFZG Working Paper Series, 07, 1-13. https://hrcak.srce.hr/146725

R Core Team. (2021). R: A Language and Environment for Statistical Computing. https://www.r-project.org/

Reise, S. P. (2014). Item response theory. The Encyclopedia of Clinical Psychology, 1-10.

Revelle, W. (2021). psych: Procedures for Psychological, Psychometric, and Personality Research. https://personality-project.org/r/psych/

Rosseel, Y. (2012). \{lavaan\}: An \{R\} Package for Structural Equation Modeling. Journal of Statistical Software, 48(2), 1-36. https://www.jstatsoft.org/v48/i02/

Rosseel, Y., Jorgensen, T. D., \& Rockwood, N. (2021). lavaan: Latent Variable Analysis. https://lavaan.ugent.be

Rothmann, S. (2008). Job satisfaction, occupational stress, burnout and work engagement as components of work-related wellbeing. SA Journal of Industrial Psychology, 34(3), 11-16. http://www.scielo.org.za/scielo.php?pid=S2071-07632008000300002\&script=sci_arttext\&tln $\mathrm{g}=\mathrm{es}$

Russell, J. A., \& Carroll, J. M. (1999). On the bipolarity of positive and negative affect. Psychological Bulletin, 125(1), 3. https://psycnet.apa.org/buy/1998-03256-001

Schaufeli, W. B. (2017). General Engagement: Conceptualization and Measurement with the Utrecht General Engagement Scale (UGES). Journal of Well-Being Assessment, 1(1), 9-24. https://doi.org/10.1007/s41543-017-0001-X

Schaufeli, W. B., \& Bakker, A. B. (2004a). Job demands, job resources, and their relationship with burnout and engagement: A multi-sample study. Journal of Organizational Behavior: The International Journal of Industrial, Occupational and Organizational Psychology and Behavior, 25(3), 293-315.

Schaufeli, W. B., \& Bakker, A. B. (2004b). Utrecht Work Engagement Scale Preliminary Manual (1.1). Occupational Health Psychology Unit, Utrecht University. https://www.wilmarschaufeli.nl/publications/Schaufeli/Test

Manuals/Test_manual_UWES_English.pdf

Schaufeli, W. B., \& Bakker, A. B. (2010). Defining and measuring work engagement: 
Bringing clarity to the concept. Work Engagement: A Handbook of Essential Theory and Research, 12, 10-24.

Schaufeli, W. B., Leiter, M. P., \& Maslach, C. (2009). Burnout: 35 years of research and practice. Career Development International, 14(3), 204-220.

Schaufeli, W. B., Salanova, M., González-Romá, V., \& Bakker, A. B. (2002). The measurement of engagement and burnout: A two sample confirmatory factor analytic approach. Journal of Happiness Studies, 3(1), 71-92. https://doi.org/https://doi.org/10.1023/A:1015630930326

Schaufeli, W. B., Taris, T. W., \& Van Rhenen, W. (2008). Workaholism, Burnout, and Work Engagement: Three of a Kind or Three Different Kinds of Employee Well-being? Applied Psychology, 57(2), 173-203. https://doi.org/https://doi.org/10.1111/j.1464-0597.2007.00285.x

Schaufeli, W., \& Salanova, M. (2011). Work engagement: On how to better catch a slippery concept. European Journal of Work and Organizational Psychology, 20(1), 39-46. https://doi.org/10.1080/1359432X.2010.515981

Schaufeli, W., \& Salanova, M. (2014). Burnout, boredom and engagement at the workplace.

Seligman, M. E. P., \& Csikszentmihalyi, M. (2014). Positive psychology: An introduction. In Flow and the foundations of positive psychology (pp. 279-298). Springer.

Sudibjo, N., \& Sutarji, T. (2020). The roles of job satisfaction, well-being, and emotional intelligence in enhancing the teachers' employee engagements. Management Science Letters, 10(11), 2477-2482. https://doi.org/http://dx.doi.org/10.5267/j.msl.2020.4.002

Tarcan, G. Y., Tarcan, M., \& Top, M. (2017). An analysis of relationship between burnout and job satisfaction among emergency health professionals. Total Quality Management \& Business Excellence, 28(11-12), 1339-1356. https://doi.org/10.1080/14783363.2016.1141659

Taris, T. W. (2006). Is there a relationship between burnout and objective performance? A critical review of 16 studies. Work \& Stress, 20(4), 316-334. https://doi.org/10.1080/02678370601065893

Taris, T. W., Ybema, J. F., \& van Beek, I. (2017). Burnout and engagement: Identical twins or just close relatives? Burnout Research, 5, 3-11. https://doi.org/10.1016/j.burn.2017.05.002

Timms, C., Brough, P., \& Graham, D. (2012). Burnt-out but engaged: the co-existence of psychological burnout and engagement. Journal of Educational Administration, 50(3), 327-345. https://doi.org/10.1108/09578231211223338

Van der Colff, J. J., \& Rothmann, S. (2009). Occupational stress, sense of coherence, coping, burnout and work engagement of registered nurses in South Africa. SA Journal of Industrial Psychology, 35(1), 1-10. http://www.scielo.org.za/scielo.php?pid=S2071-07632009000100001\&script=sci_arttext\&tln $\mathrm{g}=\mathrm{es}$

Weiss, D. J., Dawis, R. V, \& England, G. W. (1967). Manual for the Minnesota satisfaction 


\section{Macrothink \\ International Journal of Human Resource Studies \\ ISSN 2162-3058 2021, Vol. 11, No. 4}

questionnaire. Minnesota Studies in Vocational Rehabilitation.

Wickham, H., François, R., Henry, L., \& Müller, K. (2021). dplyr: A Grammar of Data Manipulation. https://cran.r-project.org/package=dplyr

Wickham, H., \& Hester, J. (2021). readr: Read Rectangular Text Data. https://cran.r-project.org/package=readr

Xie, Y. (2021). knitr: A General-Purpose Package for Dynamic Report Generation in R. https://yihui.org/knitr/

Zanon, C., Hutz, C. S., Yoo, H., \& Hambleton, R. K. (2016). An application of item response theory to psychological test development. Psicologia: Reflexao e Critica, 29(1). https://doi.org/10.1186/s41155-016-0040-x

\section{Copyright Disclaimer}

Copyright for this article is retained by the author(s), with first publication rights granted to the journal.

This is an open-access article distributed under the terms and conditions of the Creative Commons Attribution license (http://creativecommons.org/licenses/by/4.0/). 